\title{
AS RELAÇÕES PÚBLICO-PRIVADO NA EDUCAÇÃO ESPECIAL: Tendências atuais no Brasil
}

\author{
Adriana Lia Friszman de Laplane $e^{(*)}$ \\ Katia Regina Moreno Caiado \\ Mônica de Carvalho Magalhães Kassar
}

\section{INTRODUÇÃO}

Alguns estudos têm analisado diferentes faces da privatização da educação pública, seja em diferentes países, seja no Brasil. O movimento de privatização pode ser identificado na organização da administração escolar, com a presença das organizações sociais (ADRIÃO; BEZERRA, 2013), na adoção de princípios da administração privada na administração educacional pública (PERONI, 2012), na aquisição de produtos pedagógicos completos (apostilados, kits e programas para aquisição de leitura, etc.) por redes municipais e estaduais (PERONI, 2013), dentre outros exemplos.

Confirmando essa tendência, recentemente, a Secretaria de Educação do Estado de Goiás firmou convênio com o Banco Mundial (BM), envolvendo “[...] consultorias, avaliação de impacto, administração de finanças, governança das escolas" (SEDUCE, 2016; FREITAS, 2016). O convênio visa à implantação do modelo americano de escolas que recebem recursos públicos, mas têm gestão privada (escolas “charter”).

As relações entre os setores público e privado na educação não são um fato novo. Klees e Edwards Jr. (2015) esclarecem que ao longo das décadas de 1960 e 1970, o BM passou a recomendar o aumento da tributação para sustentar a expansão dos serviços sociais, mas posteriormente, nos anos 1980, tanto o BM quanto o Fundo Monetário Internacional (FMI) concluíram que seria inviável aos países em desenvolvimento aumentar impostos. Mesmo com uma revisão posterior dessa posição (WORLD BANK, 2004), Klees e Edwards Jr. (2015) explicam que

\footnotetext{
${ }^{(*}$ Adriana Laplane. Doutora Em Educação. Professora da Universidade de Campinas (Unicamp). E-mail: afriszman@hotmail.com.

Katia Caiado. Doutora em Educação. Professora na Universidade Federal de São Carlos (UFSCAR). E-mail: caiado.katia@gmail.com.
}

Mônica M. Kassar. Doutora em Educação. Professora da Unifersidade Federal do Mato Grosso (UFMS). E-mail: monica.kassar@gmail.com 
o BM admite não poder voltar a exigir que os países aumentem suas tributações. Dessa forma, diante de restrições orçamentárias impostas, inclusive por políticas internacionais anteriores, resta transferir a educação e outros direitos sociais ao setor privado.

O termo "privatização" passa a ser utilizado nas agências multilaterais e nos diferentes países. Belfield e Levin (2004), em obra publicada originalmente pela Unesco, analisam diferentes formas de privatização, como os cheques-ensino no Chile e na Colômbia, o sistema de gestão privada na Holanda, a liberalização da escola privada na República Checa, entre outros exemplos e genericamente, conceituam esse processo como "transferência de actividades, provisão e responsabilidades do governo/instituições e organizações públicas para indivíduos e organizações privadas". (LEVIN, 2001, apud BELFIELD; LEVIN, 2004, p. 17). A perspectiva que se torna hegemônica a partir desse quadro, tanto nos países desenvolvidos como nos países em vias de desenvolvimento, é que "escolas de regulação e gestão privadas - quer estejam na posse ou não de entidades públicas - são mais eficientes, mais eficazes e têm melhores resultados que as escolas geridas pelo estado" (BELFIELD; LEVIN, 2004, p. 6).

No Brasil, as relações entre os setores público e privado remontam à história do país (SAVIANI, 2011) e as suas marcas se fazem presentes na Constituição Federal de 1988, que se por um lado afirma que o acesso ao ensino obrigatório e gratuito é direito público subjetivo (art. 208, VII, $\S 1^{\circ}$ ), também garante seu oferecimento pela iniciativa privada (art. 209). Ainda, é permitida a destinação de recursos públicos a escolas comunitárias, confessionais ou filantrópicas (art. 213), sujeita ao cumprimento de certas regras pelas instituições (BRASIL, 1988). Afirma-se, assim, a ideia de que a educação é um direito da população e um dever do estado e, ao mesmo tempo é reconhecida como atividade privada, submetida, portanto, à lógica do mercado.

Na Educação Especial, a presença do setor privado é histórica (JANNUZZI, 1985; BUENO, 2004), chegando o campo de atuação a ser exemplar na relação de parceria entre os setores público e privado (ARRUDA; KASSAR; SANTOS, 2006). Jannuzzi (1985) e Rafante (2015), entre outros autores, mostram a influência decisiva de dirigentes das APAEs e da Sociedade Pestalozzi nos rumos das políticas educacionais para este setor. Como exemplo, citamos as presenças de Antônio dos Santos Clemente Filho e Justino Alves Pereira, presidentes da Federação Nacional das APAEs nos períodos 1963-1965 e 1977-1981, respectivamente, no grupo de trabalho para a formação do Centro Nacional de Educação Especial em 1973. Essa relação obedece ao princípio de intercomplementaridade de "serviços", dispositivo evidenciado na Portaria Interministerial 186/78 (BRASIL, 1978). 
Se a presença do setor privado é reconhecida pelo poder público como uma colaboração importante para a efetivação de formas diferenciadas de atendimento, para o setor privado, a busca por recursos públicos é fundamental para sua existência. As instituições privadas de caráter filantrópico no país sempre contaram com a potente organização do movimento apaeano e seu trânsito nos diferentes governos, conforme documento da Federação Nacional das APAES FENAPAES, que apresenta a constante preocupação com a eleição de seus presidentes:

Percebeu-se também uma preocupação na eleição de presidentes que facilitariam o acesso ao governo. No regime militar, seu presidente era um Coronel do Exército, que exerceu vários mandatos, em 1969 um deputado federal, na constituinte também, fato que se repetiu por diversas vezes na década de 90 e em 2004. O perfil de dirigente escolhido era de pessoas que pudessem exercer influência política. (FENAPAES, 2009, p. 12)

Ressalta-se que no primeiro estatuto da Federação Nacional das APAES (1963) já constavam orientações para a realização de convênios e parcerias com os setores público e privado (JANNUZZI, CAIADO, 2013, p. 55).

O princípio de intercomplementaridade de "serviços", presente na Portaria Interministerial 186/78, pode justificar convênios como o celebrado entre a APAE no Espírito Santo, criada em 1965, e o Governo do Estado daquela unidade federativa para cessão de professores, na década de 1970.

Registra-se que, mesmo com alterações na tendência da política educacional, como na atual proposta de educação inclusiva, a proposição de convênios tem permanecido. Gobete (2014) ao analisar os convênios firmados entre a Secretaria Municipal de Educação de Vitória e a Associação de Pais e Amigos dos Excepcionais (APAE) durante o período de 2005 a 2012 aponta para uma ambiguidade na liberação de investimentos públicos para os convênios com a instituição privada de caráter filantrópico. A pesquisadora conclui que, durante o período estudado,

[...] houve um esforço pela manutenção de convênios para prestação desses mesmos serviços, por uma instituição especializada exclusivamente em educação especial, a APAE/Vitória. Este fato marca uma opção política da SEME, em manter uma determinada interdependência com essa instituição, delegando a esta o que poderia ser assumido efetivamente pelo município. (GOBETE, 2014, p. 160).

A participação do setor privado na oferta de atendimento público foi valorizada e justificada no Plano Diretor da Reforma do Aparelho de Estado (BRASIL, 1995). A partir dessa reforma, foi elaborado o chamado Marco Legal do Terceiro Setor (BUENO; KASSAR, 2005) e as instituições especializadas de caráter assistencial, históricas na Educação Especial, foram consideradas como 
Organizações não governamentais, parte do Terceiro Setor. A Lei de Diretrizes e Bases da Educação Nacional de 1996 dispôs o estabelecimento de critérios, pelos órgãos normativos dos sistemas de ensino, para caracterizar as instituições privadas sem fins lucrativos, especializadas e com atuação exclusiva em educação especial, com vistas à obtenção de apoio técnico e financeiro pelo Poder Público (art. 60). Os últimos Planos Nacionais de Educação (PNE) citam essas organizações de forma explícita como parceiras do estado na provisão de serviços de educação especial. No PNE (2001) afirma-se no item 8.2, Diretrizes, que:

Certas organizações da sociedade civil, de natureza filantrópica, que envolvem os pais de crianças especiais, têm, historicamente, sido um exemplo de compromisso e de eficiência no atendimento educacional dessa clientela, notadamente na etapa da educação infantil. Longe de diminuir a responsabilidade do Poder Público para com a educação especial, o apoio do governo a tais organizações visa tanto à continuidade de sua colaboração quanto à maior eficiência por contar com a participação dos pais nessa tarefa. Justifica-se, portanto, o apoio do governo a essas instituições como parceiras no processo educacional dos educandos com necessidades especiais. (BRASIL, 2001).

Recentemente, durante os embates para a redação final do Plano Nacional de Educação (2014-2024), vivenciamos o esforço e a capacidade de organização e mobilização do movimento apaeano no debate sobre a Meta 4. Para essa meta, a proposta do Projeto de Lei 8035 de 2010 recomendava a seguinte redação: "Universalizar, para a população de 4 (quatro) a 17 (dezessete) anos, o atendimento escolar aos estudantes com deficiência, transtornos globais do desenvolvimento e altas habilidades ou superdotação na rede regular de ensino". Após intensa mobilização a Lei 13.005/2014, aprovou:

Universalizar, para a população de quatro a dezessete anos com de ciência, transtornos globais do desenvolvimento e altas habilidades ou superdotação, o acesso à educação básica e ao atendimento educacional especializado, preferencialmente na rede regular de ensino, com a garantia de sistema educacional inclusivo, de salas de recursos multifuncionais, classes, escolas ou serviços especializados, públicos ou conveniados. (BRASIL, 2014). (Grifo nosso.)

Essa alteração mereceu um esclarecimento nas linhas introdutórias da versão final do Plano Nacional de Educação (2014-2014):

Outra polêmica ocorreu na discussão da Meta 4 (educação especial), em relação ao atendimento educacional especializado "preferencialmente na rede pública" (expressão adotada na LDB). No debate entre atores que defendiam a educação inclusiva na rede pública e os que reivindicavam um atendimento educacional especializado complementar, foram bem-sucedidas as Apaes, que, ao apoiarem o último grupo, conseguiu que fosse mantida a expressão “preferencialmente”. (BRASIL, 2014). 
A redação da Meta 4, como vemos, mantém o histórico termo "preferencialmente", que relativiza a potência da política inclusiva e alarga o espaço da educação não regular e, ainda, se refere de forma explícita às entidades conveniadas, que remetem às instituições comunitárias, confessionais ou filantrópicas, não mencionadas nas demais metas. Além disso, entre as 19 estratégias elencadas para a Meta 4, três citam esse tipo de instituição (LAPLANE, 2015).

É interessante destacar que há uma forte tensão atualmente entre a longa história da educação especial brasileira construída com base em acordos para investimento de recursos públicos nas iniciativas privadas de caráter filantrópico e as recomendações emanadas do Banco Mundial para a área da Educação Especial. Se por um lado, o ideário neoliberal incentiva a privatização dos serviços públicos, inclusive na área da educação, a UNESCO assevera que há razões de cunho educacional, social e econômico para se desenvolver um sistema educacional mais inclusivo. Tais argumentos vêm sendo reiterados desde a Declaração de Salamanca (1994) e defendem que, "estabelecer e manter escolas para educar todas as crianças juntas é mais barato do que criar um sistema complexo de diferentes tipos de escolas especializadas para grupos de crianças" (OMS, 2011, p. 218).

As orientações acima apresentadas acabam, em princípio, por fortalecer o espaço da escola pública brasileira, pois, neste país, as instituições especializadas (escolas de educação especial) são, na maior parte dos casos, de caráter privado-assistencial. A seguir, vê-se registrada a presença das escolas especiais e sua diminuição, nos últimos anos, sob as diferentes formas administrativas.

Tabela 1: Brasil. Escolas de Educação Especial por Dependência Administrativa, no período de 2007 a 2014.

\begin{tabular}{l|l|l|l|l} 
Ano & Federal & Estadual & Municipal & Privada \\
\hline 2007 & 2 & 188 & 335 & 2135 \\
\hline 2008 & 2 & 168 & 322 & 2121 \\
\hline 2009 & 2 & 135 & 265 & 1869 \\
\hline 2010 & 2 & 119 & 255 & 1783 \\
\hline 2011 & 2 & 114 & 221 & 1744 \\
\hline 2012 & 2 & 115 & 211 & 1734 \\
\hline 2013 & 2 & 114 & 214 & 1719 \\
\hline 2014 & 2 & 116 & 203 & 1703
\end{tabular}

Fonte: MEC/INEP. Censo Escolar da Educação Básica: Microdados (2007 a 2014). Tabulação e organização de dados: Andressa Santos Rabelo. 
O movimento evidenciado pelos dados da tabela obedece à implementação de políticas inclusivas, que tomou maior fôlego a partir da década de 1990. Chama a atenção, ainda, o fato de que as escolas privadas constituem ampla maioria nessa forma de atendimento. Em 2014, do total de 2.024 escolas, $1.703(84,14 \%)$ eram privadas.

A presença marcante da iniciativa privada não implica, necessariamente, independência do setor público. Contrariamente, as entidades privadas subsistem, em grande medida, de recursos provenientes do setor público, como poderá ser observado a seguir.

\section{FINANCIAMENTO DA EDUCAÇÃO ESPECIAL}

Uma das instâncias que balizam as relações entre o público e o privado e ajudam a demarcar esses espaços diz respeito ao financiamento. O decreto 6.278, de 2007 admite, a partir de 2008:

[...] para efeito da distribuição dos recursos do FUNDEB, o cômputo das matrículas efetivadas na educação especial oferecida por instituições comunitárias, confessionais ou filantrópicas sem fins lucrativos, com atuação exclusiva na educação especial, conveniadas com o poder executivo competente. (BRASIL, 2007).

A garantia de destinação de recursos do Fundo de Manutenção e Desenvolvimento da Educação Básica e de Valorização dos Profissionais da Educação (Fundeb) aos estados e municípios, em razão dos convênios existentes entre estes e as instituições com atuação exclusiva na educação especial, se aplica também no caso da matrícula no Atendimento Educacional Especializado (AEE), ofertada no contraturno aos alunos que frequentam o ensino regular. A prática da dupla matrícula (no ensino regular e no AEE) foi oficializada pelo Decreto 7.611, que também assegurou apoio técnico e administrativo às instituições (BRASIL, 2011).

O mecanismo de financiamento garante a estados e municípios a distribuição de recursos do Fundeb em função de matrículas nas instituições conveniadas, preservando assim o seu espaço na educação de alunos com deficiência de forma coerente com a relação histórica entre o Estado e as instituições privado-assistenciais.

No período de 2003 a julho de 2013, foi destinado em caráter suplementar a essas instituições, um total de R \$101.693.049,81, pelo Programa Dinheiro Direto na Escola (PDDE) e R \$ 352 milhões pelo Programa Nacional de Alimentação Escolar (PNAE). Os recursos previstos para repasse às instituições especializadas pelo PDDE atenderam 2.329 entidades privadas de educação especial em 2013 e a previsão de recursos para aquele ano dobrou em relação ao repasse de 2012. De 2009 a 2012, o Ministério da Educação transferiu R\$ 2 bilhões para a efetivação de convênio 
das Secretarias de Educação com instituições filantrópicas, confessionais, sem fins lucrativos, especializadas em educação especial, assegurando a dupla matrícula no atendimento educacional especializado (AEE), conforme Decreto 6.253/2007 (BRASIL, 2016a, p.135, 136).

Além dos repasses federais, essas instituições recebem também verbas de secretarias estaduais e municipais. Como exemplo, Laplane e Caiado (2012, p.121) apresentam notícia veiculada na página WEB da Secretaria da Educação do Estado de São Paulo, em que o secretário Paulo Renato Souza afirmava em entrevista, já na década de 1990:

O Estado de São Paulo está em um processo crescente de apoio às APAEs. A parceria começou em 1995, ainda na administração do governador Mário Covas, quando atendíamos 133 unidades, beneficiando cerca de 13 mil alunos. Hoje, estamos assinando 294 convênios, atendendo cerca de 33 mil alunos. No primeiro ano do governo José Serra repassamos R\$ 65 milhões e hoje, estamos repassando quase R $\$ 78$ milhões.

A consulta aos dados divulgados no Portal da Transparência do Estado de São Paulo revela que o valor desembolsado pelo estado a essas instituições entre 2014 e 2015 foi de R $\$ 182$ milhoes, sendo o valor total do convênio de $\mathrm{R} \$ 310$ milhoes. Observa-se, assim, que o valor dos repasses tem aumentado entre a década de 1990 e a presente data. (SÃO PAULO, 2016).

Outro exemplo das relações entre o estado e as instituições privado-assistenciais pode ser encontrado no Paraná. Em 2013, a Lei 17.656 cria o Programa Estadual de Apoio Permanente às Entidades Mantenedoras de Escolas que ofertam Educação Básica, na modalidade Educação Especial, denominado 'Todos Iguais pela Educação' (PARANÁ, 2013). Esse Programa torna obrigatório, para as escolas básicas de Educação Especial privado-filantrópicas, os mesmos direitos e recursos públicos destinados às escolas da rede estadual de ensino. A medida inclui os programas de alimentação e transporte escolar, construção, ampliação e reforma das unidades escolares, suprimento de mobiliários, equipamentos e materiais e capacitação; assim como a designação de servidores estaduais (professores, pedagogos e agentes educacionais I e II).

Esse processo, no estado do Paraná, vem constituindo-se, ao menos, desde 2011, com a Instrução 12/2011 SUED/SEED, que autorizou a alteração do nome das escolas de educação especial para escolas de Educação básica, na modalidade de educação especial. Essa ação não apenas muda o nome dessas instituições e cessa definitivamente a existência formal das "Escolas de Educação Especial”, como passa a integrá-las ao sistema estadual de ensino. Essa mesma instrução antecipa o Programa a ser lançado em 2013, pois estabelece que:

As escolas de Educação Básica na Modalidade de Educação Especial mantidas por entidades que comprovarem finalidade não lucrativa e conveniadas com a SEED terão garantido 
tratamento igual ao dispensado às demais escolas da Rede Pública, conforme critérios estabelecidos pela SEED. (PARANÁ, 2011).

Com a inclusão, nesse processo, das entidades que comprovem finalidade não lucrativa e as conveniadas com a Secretaria de Educação daquele estado, garante-se a distribuição dos recursos públicos para essas entidades do setor privado.

Essa medida é, também, uma tentativa de fortalecer a categoria "escola" das entidades de educação especial, logrando, de certo modo, o movimento impulsionado pela política de educação inclusiva que tem incentivado em todo o país a matrícula de alunos da Educação Especial nas escolas comuns, como pode ser observado a seguir:

Tabela 2: Brasil. Matrículas de alunos de Educação Especial nas escolas comuns, por Dependência Administrativa no Brasil no período de 2007 a 2014.

\begin{tabular}{l|l|l|l|l|l}
\hline Ano & \multirow{2}{*}{$\begin{array}{l}\text { Total de } \\
\text { Matrícula }\end{array}$} & & \multicolumn{2}{l}{ Público } & \multicolumn{2}{l}{ Privado } \\
\cline { 3 - 6 } & & Matrícula & Percentual & Matrícula & Percentual \\
\hline 2007 & 306136 & 285923 & 93,40 & 20213 & 6,60 \\
\hline 2008 & 375775 & 352638 & 93,84 & 23137 & 6,16 \\
\hline 2009 & 387031 & 365796 & 94,51 & 21235 & 5,49 \\
\hline 2010 & 484332 & 457236 & 94,40 & 27096 & 5,60 \\
\hline 2011 & 558423 & 525812 & 94,16 & 32611 & 5,84 \\
\hline 2012 & 620777 & 583619 & 94,02 & 37158 & 5,98 \\
\hline 2013 & 648921 & 609839 & 93,98 & 39082 & 6,02 \\
\hline 2014 & 698768 & 655375 & 93,80 & 43393 & 6,20 \\
\hline
\end{tabular}

Fonte: MEC/INEP. Censo Escolar da Educação Básica: Microdados (2007 a 2014). Dados tabulados e organizados por Andressa S. Rebelo. Percentual referente ao total de matrículas, somadas as de escolas públicas e privadas.

Observa-se, na tabela 2, o crescimento progressivo de matrículas de alunos com deficiência, transtornos globais do desenvolvimento e altas habilidades/superdotação nas escolas comuns, sob todas as formas de administração no país. Mesmo com o crescimento dessa forma de matrícula no setor privado, o setor público registra mais de $90 \%$ das matrículas dessa forma de atendimento.

Os números confirmam que o setor privado vem mantendo-se nas formas de educação exclusiva/especial, necessitando, para isso, de recursos públicos. Conforme informações da Agência de Notícias do Paraná (2013a), com a equiparação de recursos, os investimentos em Educação Especial para o ano de 2014 foram previstos em $\mathrm{R} \$ 388$ milhões para renovação e ampliação de convênios com 413 escolas e instituições.

Os exemplos de diferentes estados e instituições permitem observar a existência de uma diversidade de mecanismos que se somam para garantir, por diferentes vias, o financiamento das instituições que atuam na área de Educação Especial. Assim, recursos públicos vêm garantindo a 
existência das formas exclusivas de atendimento, a despeito da propagação da política de educação inclusiva. A tabela 3 (a seguir) mostra que apesar da diminuição dos números absolutos de matrículas em escolas exclusivas de educação especial, proporcionalmente, o setor privado tem crescido nessa forma de atendimento: de responsável por $78,87 \%$ das matrículas em escolas especiais em 2007 passa a 82,78\%, em 2014.

Tabela 3. Brasil. Matrículas de alunos de Educação Especial nas escolas exclusivamente especiais, por Dependência Administrativa no Brasil no período de 2007 a 2014.

\begin{tabular}{|c|c|c|c|c|c|}
\hline \multirow[t]{2}{*}{ Ano } & \multirow{2}{*}{$\begin{array}{l}\text { Total de } \\
\text { Matrícula }\end{array}$} & \multicolumn{2}{|l|}{ Público } & \multicolumn{2}{|l|}{ Privado } \\
\hline & & Matrícula & Percentual & Matrícula & Percentual \\
\hline 2007 & 270.742 & 57.216 & 21,13 & 213.526 & 78,87 \\
\hline 2008 & 245.443 & 50.448 & 20,55 & 194.995 & 79,45 \\
\hline 2009 & 199.257 & 38.862 & 19,50 & 160.395 & 80,50 \\
\hline 2010 & 172.016 & 33.176 & 19,28 & 138.840 & 80,72 \\
\hline 2011 & 156.385 & 29.400 & 18,80 & 126.985 & 81,20 \\
\hline 2012 & 168.488 & 30.200 & 17,92 & 138.288 & 82,08 \\
\hline 2013 & 163.968 & 28.089 & 17,13 & 135.879 & 82,87 \\
\hline 2014 & 161.043 & 27.736 & 17,22 & 133.307 & 82,78 \\
\hline
\end{tabular}

Fonte: MEC/INEP. Censo Escolar da Educação Básica: Microdados (2007 a 2014). Dados tabulados e organizados por Andressa S. Rebelo.

Delineia-se, assim, um panorama em que o setor privado concentra as matrículas em escolas de educação especial, financiado pelo setor público, enquanto que a escola pública é responsável pela inclusão de alunos com deficiência nas escolas comuns.

\section{ORGANIZAÇÕES DA SOCIEDADE CIVIL: O CASO DA EDUCAÇÃO ESPECIAL}

O Marco regulatório das organizações da sociedade civil (2015) é outra iniciativa recente cujo histórico aponta para o protagonismo das instituições privado-assistenciais. Em 2011, o Grupo de Trabalho Interministerial (GTI) ${ }^{1}$ instituído pelo Decreto 7.568/2011, foi encarregado de elaborar o documento. O GTI contou com a composição paritária de representantes do governo federal e da sociedade civil. Entre as 14 organizações participantes, escolhidas pela "Plataforma por um Novo Marco Regulatório para as Organizações da Sociedade Civil” estava a Fenapae. De acordo com o documento, a agenda do Marco Regulatório visa à valorização da participação das organizações da sociedade civil na formulação, execução e avaliação de políticas públicas. Ela deve também

\footnotetext{
${ }^{1}$ Grupo que agregou organizações, coletivos, redes e movimentos sociais de várias origens para reivindicar participação na discussão sobre o novo marco regulatório.
} 
garantir: "a plena participação, a transparência na aplicação de recursos públicos, a efetividade na execução dos projetos e a inovação das tecnologias sociais”. (BRASIL, 2015a; p. 28).

Uma série de estudos, realizados pelo Instituto de Pesquisa Econômica Aplicada (IPEA) nos últimos anos, caracteriza essas organizações. De acordo com um dos trabalhos (LÓPES; BARONE, 2013), em 2011 existiam no Brasil 303.000 organizações da sociedade civil (OSCs). Dessas, 90\% eram associações privadas. No que se refere a financiamento, no período de 2000 a 2010 , os setores de Ciência e Tecnologia e Saúde concentravam $42 \%$ das transferências a entidades sem fins lucrativos (ESFLs). A Educação respondia por 8\% (IPEA, 2012). O estudo conclui que o estado brasileiro, nos níveis federal, estadual e municipal, aumentou, no período, o volume de transferências a ESFLs.

A Lei 13.019, de 31 de julho de 2014, alterada pela Lei 13.204, de 14 de dezembro de 2015, [...] estabelece o regime jurídico das parcerias voluntárias, envolvendo ou não transferências de recursos financeiros, entre a administração pública e as organizações da sociedade civil, em regime de mútua cooperação, para a consecução de finalidades de interesse público; define diretrizes para a política de fomento e de colaboração com organizações da sociedade civil; [...]. (BRASIL, 2015a).

A Lei define e detalha os termos da colaboração ou fomento, formalização e execução de parcerias, prestação de contas, responsabilidade e sanções, entre outros. O Decreto 8.726, de 27 de abril de 2016, que regulamenta a Lei, cria o Conselho Nacional de Fomento e Colaboração CONFOCO:

[...] órgão colegiado paritário de natureza consultiva, integrante da estrutura do Ministério do Planejamento, Orçamento e Gestão, com a finalidade de divulgar boas práticas e de propor e apoiar políticas e ações voltadas ao fortalecimento das relações de parceria das organizações da sociedade civil com a administração pública federal. (Art. 83).

O mesmo artigo dispõe que o Conselho será constituído por representantes de diferentes ministérios em paridade com representantes das organizações (11 representantes de cada setor).

A nova legislação sinaliza o avanço das discussões sobre as relações entre as organizações da sociedade civil e as suas participações como parceiras do estado em ações, projetos e programas que abrangem um conjunto heterogêneo de áreas e cujos objetivos estão relacionados ao âmbito público. Ainda, as diferentes histórias dessas parcerias, no que se refere a cada área, singularizam as suas formas de constituição e os seus efeitos nas políticas públicas. Como já mostrado, no caso da educação especial, a história refere uma participação inicial maior das instituições privadas do que 
de instituições estatais na provisão de serviços destinados especificamente à população com deficiência (instituições/escolas especiais).

Acrescenta-se, ainda, que o debate sobre o financiamento na área de educação especial, deveria considerar outros elementos pouco conhecidos entre nós. Um refere-se ao número de pessoas com deficiência no país em idade escolar fora da escola ou não alfabetizadas. Em 1994, documento do Ministério da Educação divulgava que ao considerar a estimativa de $10 \%$ da população com alguma deficiência no Brasil, "apenas cerca de 1\% recebe, atualmente, atendimento educacional" (MEC, 1994, p. 8). Treze anos depois, em 2007, o Ministério da Previdência Social e o Ministério da Educação realizaram um cruzamento entre suas bases de dados e afirmaram que

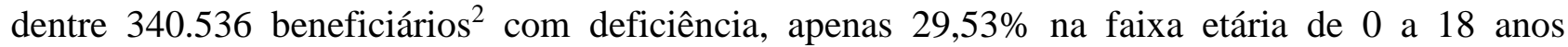
estavam matriculados em escolas, sendo que 70,47\% não tinham registro no sistema regular de ensino (CAIADO et al., 2014, p. 245). Em 2013, dentre 497.827 beneficiários com deficiência, $35,89 \%$ ainda estava fora da escola, o que representava 178.681 crianças e jovens com deficiência sem escola no país (BRASIL, 2016b, p.43-45). Em 2015, um documento do governo federal que pretende ser a linha de base para avaliação do PNE (2014-2024), para a meta 4 considera 2 indicadores: $\mathrm{O}$ indicador 4A refere-se à taxa de crianças e adolescentes de 4 a 17 anos que, segundo Censo Demográfico de 2010, não conseguiam de modo algum ou têm grande dificuldade para enxergar, ouvir, caminhar ou subir degraus, ou ainda possuíam alguma deficiência mental/intelectual permanente que limitavam suas atividades e que frequentavam alguma escola ou creche, de qualquer modalidade. Segundo o documento, essa taxa é de 85,8\%. O indicador 4B considera as matrículas em classes comuns do ensino regular elou EJA da educação básica de alunos de 4 a 17 anos com deficiência, transtornos globais do desenvolvimento e altas habilidades ou superdotação, que em 2013, correspondia a 85,5\% das matrículas (BRASIL, 2015b). As diferentes informações apontam para um desconhecimento da situação real de crianças e adolescentes desse grupo sem escolarização (em escolas públicas ou não) e, com as alterações em curso, como as do estado do Paraná, o acesso a elas fica mais difícil.

Outro elemento, ainda, a ser considerado refere-se ao fato de que o financiamento das instituições privado-assistenciais pode estar sendo uma forma de evitar pressão no sistema público de saúde do país. Um argumento para essa hipótese pode ser encontrado em Corrêa (2005), que, ao

\footnotetext{
${ }^{2}$ Beneficiários com deficiência são pessoas com direito a receber um salário mínimo ao comprovarem não possuir meios de prover a própria manutenção. Direito regulamentado como Benefício de Prestação Continuada, Lei $8.742 / 1993$.
} 
analisar o processo de municipalização da educação especial em Campo Grande (MS) após o processo de Reforma do Estado brasileiro, mostra que o atendimento no setor da saúde dos alunos com deficiências das escolas públicas (o que nessa população é bastante frequente) ocorre em instituições privadas conveniadas com a secretaria municipal.

\section{CONSIDERAÇÕES FINAIS}

A tentativa de compreender a especificidade das relações entre os setores público e privado na educação especial, no contexto do movimento privatista que tem caracterizado a educação, nos levou a examinar neste estudo diferentes aspectos que incidem nessas relações.

Na educação especial, o setor privado tem longa tradição no Brasil e presença constante nas políticas públicas. Embora a política inclusiva esteja promovendo a matrícula da população alvo dessa modalidade educacional nas escolas regulares e classes comuns e esse atendimento esteja ocorrendo principalmente pelas escolas públicas, as instituições com atuação exclusiva na educação especial, que atendem majoritariamente aos alunos matriculados em escolas especiais, têm recebido recursos públicos de forma crescente.

As transferências do governo federal, estados e municípios, por meio de programas, convênios e parcerias garantem verbas de capital e custeio às instituições, que se caracterizam como Organizações da Sociedade Civil.

Considerando os dados de matrícula, as informações sobre financiamento, os documentos e a legislação recente que normatizam as parcerias entre as OSCs e o estado, concluímos que, no contexto político atual, a tendência é de aumento da participação dessas instituições tanto no que se refere ao financiamento como à formulação e execução de políticas públicas.

Esboça-se um quadro preocupante quando se considera ainda, a Proposta de Emenda Constitucional 241 (PEC 241/2016), que ao instituir um novo regime fiscal, ocasionará o congelamento dos recursos destinados à Educação, com evidente prejuízo para a expansão do atendimento educacional e para a qualidade dos serviços oferecidos.

A tendência apresentada neste texto aponta para o incremento da interdependência das esferas pública e privada, da complexidade crescente das relações e da presença marcante do setor privado-assistencial na Educação Especial, mesmo em tempos de política de educação inclusiva. 


\section{REFERÊNCIAS}

ADRIÃO, T.; BEZERRA, E.P. O setor não lucrativo na gestão da educação pública: corresponsabilidade ou debilidade. Currículo sem Fronteiras, v. 13, n. 2, p. 256-268, maio/ago. 2013. Disp.: <http://www.curriculos emfronteiras. org/vol13iss2articles/adriao-bezerra.pdf>. Acesso: 16 maio 2016.

ARRUDA, E.E.; KASSAR, M.C.M.; SANTOS, M.M. Educação especial: o custo do atendimento de uma pessoa com necessidades especiais em instituições pública estatal e não estatal, em MS, 2004. In: NERES, C.C.; LANCILLOTTI, S. S.P. (Orgs.). Educação Especial em foco: questões contemporâneas. Campo Grande: Uniderp, 2006. v. 1, p. 89-116.

BELFIELD, C.R.; LEVIN, H.M. A privatização da educação: Causas e implicações. Originalmente publicado pela Organização Cultural, Científica e Educacional das Nações Unidas (Unesco-HEP). Lisboa: Edições ASA, 2004.

BRASIL. Censo escolar da educação básica. MEC/INEP. Brasília, 2007, 2008, 2009, 2010, 2011, $2012,2013,2014$. Disp.: <http://portal.inep.gov.br/basica-levantamentos-microdados>. Acesso: 10 ago. 2015.

Constituição (1988). Constituição da República Federativa do Brasil. Diário Oficial da União. Brasília: Congresso Nacional, 05 out. 1988. Anexo.

Declaração de Salamanca. Sobre Princípios, Políticas e Práticas na Área das Necessidades Educativas Especiais. Disp.: <http://portal.mec.gov.br/seesp/arquivos/pdf/salamanca.pdf〉. Acesso: 12 maio 2016.

Decreto 6.278/2007. Altera o Decreto 6.253, de 13 de novembro de 2007. Dispõe sobre o Fundo de Manutenção e Desenvolvimento da Educação Básica e de Valorização dos Profissionais da Educação (Fundeb) e regulamenta a Lei 11.494/2007. Disp.: <https://www.planalto.gov.br/ccivil_03/_Ato2007-2010/2007/Decreto/D6278. htm>. Acesso: 20 junho 2016.

Decreto 7.611 2011. Dispõe sobre a educação especial, o atendimento educacional especializado e dá outras providências. Disp.: <http://www.planalto.gov.br/ccivIl_03/_Ato2011-2014/2011/Decreto/D7611.htm>. Acesso: 20 jun. 2016.

INEP. Plano Nacional de Educação (PNE) 2014-2024: Linha de Base. Brasília, DF: Inep, 2015 b.

Lei 10.172, de 9 de janeiro de 2001. Aprova o Plano Nacional de Educação. Disp.: <https://www.planalto.gov.br/ccivil_03/leis/leis_2001/110172.htm>. Acesso: 12 de maio de 2016.

Lei 13.005, de 25 de junho de 2014. Aprova o Plano Nacional de Educação - PNE. Disp.: <http://www.planalto.gov.br/ccivil_03/_Ato2011-2014/2014/Lei/L13005.htm>. Acesso: 15 maio 2016.

Lei 13.204, de 14 de dezembro de 2015. Altera a Lei 13.019, de 31 de julho de 2014, que estabelece o regime jurídico das parcerias voluntárias, envolvendo ou não transferências de recursos financeiros, entre a administração pública e as organizações da sociedade civil, em regime de mútua cooperação, para a consecução de finalidades de interesse público. 2015a. Disp.: 〈https://www.planalto.gov.br/ccivil_03/_Ato2015-2018/2015/Lei/ L13204.htm\#art1〉. Acesso: 12 maio 2016.

MEC/MPAS. Portaria Interministerial 186, de 10 de março de 1978. Brasília, 1978.

Ministério da Administração e Reforma do Estado. Plano diretor da reforma do aparelho de estado. Brasília, 1995.

MEC. Nota Técnica 101/2013/MEC/SECADI/DPEE. In: A Consolidação da inclusão escolar no Brasil, 2003 a 2016. Brasília, DF: MEC, 2016, p. 135-136. 2016a Disp.: <http://portal.mec.gov.br/index.php?option=com_ docman\&view=download\&alias=17237-secadi-documento-subsidiario-2015\&category_slug=marco-2015-pdf\&Itemid= 30192>. Acesso: 20 junho 2016.

MEC. Nota Técnica 16/2016/MEC/SECADI/DPEE. A Consolidação da inclusão escolar no Brasil, 2003 a 2016. Brasília, DF: MEC, 2016, p. 43-45. 2016b. Disp.: <http://portal.mec.gov.br/index.php?option=com_docman\& view=download\&alias=17237-secadi-documento-subsidiario-2015\&category_slug=marco-2015-pdf\&Itemid=30192> . Acesso: 20 junho 2016.

BUENO, C.C.O.; KASSAR, M.C.M. Público e privado: a educação especial na dança das responsabilidades. In: ADRIÃO, T.; PERONI, V.M.V. (Orgs.). O público e o privado na Educação: interfaces entre Estado e sociedade. São Paulo: Xamã, 2005. 
BUENO, J. G. S. Educação Especial Brasileira: integração/segregação do aluno diferente. 2. ed. São Paulo: Educ, 2004.

CAIADO, K.R.M. et al. Deficiência e desigualdade social: o recente caminho para a escola. In: Cadernos Cedes, Campinas, SP, v. 34, n. 93, p. 241-260, maio-ago. 2014. Disp.: <http://www.scielo.br/pdf/ccedes/v34n93/0101-3262ccedes-34-93-0241.pdf>. Acesso: 25 junho 2016.

CÂMARA DOS DEPUTADOS. PEC 241. Altera o Ato das Disposições Constitucionais Transitórias, para instituir o Novo Regime Fiscal. Disp.: <http://www.camara.gov.br/proposicoesWeb/fichadetramitacao?idProposicao $=2088351>$. Acesso: 27 jun. 2016.

CORRÊA, N.M. A construção do processo de municipalização da educação especial em Campo Grande no período de 1996 a 2004. Dissertação (Mestrado em Educação) - UFMS, 2005.

FENAPAES. Planejamento Estratégico 2009-2011. Disp.: 〈http://portal.apae.com.br/Arquivo/view/10027>. Acesso: 2 out. 2012.

FGV PROJETOS; SECRETARIA-GERAL DA PRESIDÊNCIA DA REPÚBLICA. Pesquisa sobre as organizações da sociedade civil e suas parcerias com o governo federal. Rio de Janeiro/Brasília: FGV Projetos/Secretaria-Geral da Presidência da República, 2014. Disp.: http://www.secretariadegoverno.gov.br/iniciativas/mrosc/estudos-e-pesquisas/ sumario-executivo-fgv.pdf>. Acesso: 27 junho 2016.

FREITAS, L.C. Escolas Charter. Avaliação Educacional. Blog do Freitas. Disp.: <https://avaliacaoeducacional.com/ category/os-novos-reformadores/privatizacao/escolas-charters/. Acesso: 27 junho 2016.

GOBETE, G. Educação especial no município de Vitória/ES no período de 1989 a 2012: políticas e direito à educação. Tese (Doutorado) - Programa de Pós-Graduação em Educação da Universidade Federal do Espírito Santo. Vitória. 2014.

INSTITUTO DE PESQUISA ECONÔMICA APLICADA (Ipea). Transferências federais a entidades privadas sem fins lucrativos (1999-2010). Texto para Discussão 1.778, 2012. Disp.: <https://issuu.com/mrosc/docs/2012-ipea〉. Acesso: 20 junho 2016.

JANNUZZI, G.M. A educação do deficiente no Brasil: dos primórdios ao início do século XXI. Campinas: Autores Associados, 2004.

; CAIADO, K.R.M. Apae: 1954 a 2011, algumas reflexões. Campinas, SP: Autores Associados, 2013.

A luta pela educação do deficiente mental no Brasil. São Paulo: Cortez: Autores Associados, 1985.

KLEES, S.J.; EDWARDS JR., D. Brent. Privatization of education: experiences from the united states and elsewhere. Rev. Bras. Educ., Rio de Janeiro, v. 20, n. 60, p. 11-30, mar. 2015. Disp.: <http://www.scielo.br/scielo. php?script=sci_arttext\&pid=S1413-24782015000100011\&lng=pt\&nrm=iso>. Acesso: 05 julho 2016.

LAPLANE, A.L.F. O que os dados do Censo Escolar revelam sobre as barreiras à inclusão escolar? Revista educação e fronteiras on-line, v. 5, p. 21-42, 2015. Disp.: <http://ojs.ws.ufgd.edu.br/index.php?journal=educacao\&page=article \& op=view\&path\%5B\%5D=3762\&path\%5B\%5D=pdf_281>. Acesso: 15 junho 2016.

LAPLANE, A.L.F.; CAIADO, K.R.M. Uma década de educação especial no Brasil. In: JEFFREY, D.C., AGUILAR, L. E. (Orgs.). Política Educacional Brasileira: análises e entraves. Campinas, SP: Mercado de Letras, 2012.

LOPEZ, F.G.; BARONE, L.S. As organizações da sociedade civil e as políticas públicas federais (2003-2011). Boletim de Análise Institucional. Brasília: Ipea, 2013. Disp.: <http://repositorio.ipea.gov.br/bitstream/11058/5912/1/BAPI _n03_p61-70_NP_Organizacoes_Diest_2013-mar.pdf>. Acesso: 20 jun. 2016.

ORGANIZAÇÃO MUNDIAL DE SAÚDE (OMS). Relatório mundial sobre a deficiência, 2011. Disp.: <http://www. pessoacomdeficiencia.sp.gov.br/usr/share/documents/RELATORIO_MUNDIAL_COMPLETO.pdf>. Acesso: 23 jun. 2016.

PARANÁ. Agência de Notícias do Paraná. Apoio do Paraná para as escolas de Apaes vira lei pioneira no país. Publicado em de 15 de agosto de 2013. 2013a. Disp.: <http://www.aen.pr.gov.br/modules/noticias/article.php? storyid=76101>. Acesso: 23 jun. 2016.

Lei 17.656, 12 de Agosto de 2013. Institui o Programa Estadual de Apoio Permanente às Entidades Mantenedoras de Escolas que ofertam Educação Básica na Modalidade Educação Especial denominado "Todos iguais pela educação". Diário Oficial 9.019, 12 ago. 2013b. 
PARANÁ. SEE. Superintendência da Educação. Instrução 012/2011. Disp.: <http://www.educacao.pr.gov.br/arquivos /File/instrucoes\%202011\%20sued\%20seed/instrucao0122011sued.pdf>. Acesso: 5 jul. 2016.

PERONI, V.M.V.A gestão democrática da educação em tempos de parceria entre o público e o privado. Pro-Posições, Campinas, v. 23, n. 2, p. 19-31, aug. 2012. Disp.: <http://dx.doi.org/10.1590/S0103-73072012000200003>. Acesso: 14 maio 2016.

PERONI, V.M.V. As relações entre o público e o privado nas políticas educacionais no contexto da terceira via. Currículo sem Fronteiras, v. 13, n. 2, p. 234-255, maio/ago. 2013. Disp.: <http://www.curriculosemfronteiras.org/vol 13iss2articles/peroni.pdf>. Acesso: 14 maio 2016.

RAFANTE, H. C. Política de educação especial no Brasil: a relação entre o estado, a sociedade civil e as agências internacionais na criação do CENESP. In: ANPEd. Anais da 37 ${ }^{\mathbf{a}}$ Reunião... Florianópolis, SC, 2015. Disp.: <http://37reuniao.anped.org.br/wp-content/uploads/2015/02/Trabalho-GT15-3916.pdf>. Acesso: 10 maio 2016.

SÃO PAULO. Portal da transparência. Disp.: <http://www.transparencia.sp.gov.br/>. Acesso: 25 junho 2016.

SAVIANI, D. O estado e a promiscuidade entre o público e o privado na história da educação brasileira. In: SAVIANI, D. (Org.). Estado e políticas Educacionais na História da Educação Brasileira. Vitória, ES: Edufes, 2011.

SEDUCE. Secretaria de Estado de Educação, Cultura e Esporte. Goiás. 2016. Disp.: <http://portal.seduc.go.gov.br/ SitePages/Noticia.aspx?idNoticia=2010>. Acesso: 29 jun. 2016.

WORLD BANK. World Development Report 2004: making services work for poor people. Washington, DC: World Bank, 2004. Disp.: <https://openknowledge.worldbank.org/bitstream/handle/10986/5986/WDR\%202004\%20-\%20 English.pdf?sequence=1>. Acesso: 5 julho 2016 . 


\section{RESUMO}

A privatização da educação tem avançado no mundo e no Brasil. As diretrizes dos organismos internacionais não são alheias a esse processo, resultando, nas proposições locais, em arranjos de diversas naturezas: sistemas públicos compram pacotes de ensino privados que incluem materiais e treinamento para os docentes; empresas privadas sustentam financeiramente escolas públicas e controlam, por meio de programas e projetos, o que é ensinado. Na Educação Especial, o setor privado tem longa tradição e, no Brasil, está fortemente enraizado e interligado às políticas públicas. O presente estudo discute e analisa exemplos que podem ser tomados como indicadores das tendências que as relações entre os setores público e privado têm assumido nessa modalidade.

Palavras-chave: políticas públicas; educação especial; privatização; parceria público-privada.

\section{PUBLIC-PRIVATE RELATIONSHIPS IN SPECIAL EDUCATION: CURRENT TRENDS IN BRAZIL}

\section{ABSTRACT}

The privatization of education has grown throughout the world, included Brazil. The guidelines of international organisms are not strange to this process that has resulted in arrangements of diverse nature. Public systems buy educational packages that comprise teaching materials and teacher training; private companies financially sustain public schools and control, by means of programs and projects, what is being taught. In Special Education the private sector has a long tradition and in Brazil it is profoundly rooted and intertwined with public policies. The present article discusses and analyzes examples that can be taken as indicators of the most important trends that the relationship between the public and the private spheres has assumed regarding Special Education.

Keywords: public policies; special education; privatization; public-private partnership.

Submetido abril 2016

Aprovado jun. 2016 